\title{
MULHERES VENEZUELANAS NO ESTADO DE RORAIMA: DESAFIOS DE PROTEÇÃO DIANTE DA NECESSIDADE DE POLÍTICAS PÚBLICAS INTERSECCIONAIS
}

\author{
VENEZUELAN WOMEN IN THE STATE OF RORAIMA: CHALLENGES \\ OF PROTECTION BEYOND THE NEED FOR INTERSECTIONAL PUBLIC \\ POLICIES
}

\author{
Carolina Becker Peçanha* \\ Karen Carvalho Rosaboni ${ }^{* *}$ \\ Maria Eduarda De'Carli Santos Moury Fernandes ${ }^{* * *}$
}

\begin{abstract}
RESUMO
O artigo tem como objetivo estabelecer o diálogo entre fluxos migratórios mistos e os desafios de proteção às mulheres venezuelanas, que atravessam a fronteira até o Brasil, a partir da necessidade de uma perspectiva interseccional das políticas públicas. Por meio da pesquisa bibliográfica, pretendemos fazer uma abordagem teórica sobre a migração feminina venezuelana no estado de Roraima. Utilizam-se insumos teóricos para um breve estudo de questões de gênero e a "feminização das migrações". Nesse sentido, o seu desdobramento esbarra na migração sexual e prostituição, seguida de um questionamento sobre a maneira como o aparato estatal lida com a vulnerabilidade desta população. Diante das dificuldades encontradas, pretende-se analisar a necessidade de políticas públicas interseccionais que contemplem a não homogeneidade da população venezuelana, com especial enfoque nas mulheres migrantes.
\end{abstract}

Palavras-chave: Fluxos migratórios mistos. Mulheres venezuelanas. Políticas públicas.

\begin{abstract}
The article aims to establish the dialogue between mixed migratory flows and the challenges of protecting Venezuelan women, who cross the border to Brazil, from the need for an intersectional perspective of public policies. Through bibliographical research, we intend to make a theoretical approach on the Venezuelan female migration in the state of Roraima. Theoretical inputs are used for a brief study of gender issues and the "feminization of migrations". In this sense, its unfolding is based on sexual migration and prostitution, followed by a questioning about how the state apparatus deals with the vulnerability of this population. In view of the difficulties encountered, it is intended to analyze the need for intersectional public policies that contemplate the non-homogeneity of the Venezuelan population, with a special focus on migrant women.
\end{abstract}

Keywords: Mixed migratory flows. Venezuelan women. Public policy.

\footnotetext{
*Graduada em Ciências Sociais pela Universidade Federal de Santa Catarina (UFSC), Florianópolis, SC (2013)

${ }^{* *}$ Mestranda em Direitos Humanos e Cidadania pela Universidade de Brasília (UnB), Brasília, DF.

*** Expert em Reassentamento no Alto Comissariado das Nações Unidas para Refugiados (ACNUR). Graduada em Direito pela Universidade Federal de Pernambuco (2014). Pós-graduada em Direito Administrativo pela Uniderp (2015).
} 


\section{INTRODUÇÃO}

Os últimos anos foram marcados por um nível sem precedentes de pessoas se movimentando pelo mundo, em que os deslocamentos forçados atingiram a sua maior marca desde a Segunda Guerra Mundial. Pessoas têm migrado para outros países pelos mais diversos fatores: crises econômicas, escassez de alimentos, guerras, catástrofes ambientais, perseguições e violações generalizadas de direitos humanos.

Ao longo da história, as maneiras de mobilidade não são estáticas e passaram por um constante processo de mudança, com um aumento dos deslocamentos frequentes e de curta duração, em substituição aos tradicionais movimentos de longa duração e episódicos. Vivencia-se o período da hipermobilidade (MOTA, 2011) e do aumento dos chamados fluxos mistos. Comumente, as pessoas que se deslocam para outros países compartilham das mesmas rotas e meios de deslocamento, e, independentemente da categoria migratória, as pessoas estão sujeitas aos mesmos desafios e vulnerabilidades.

À vista disso, os "fluxos mistos" contemplam movimentos complexos e, considerando a heterogeneidade de tais deslocamentos, é essencial sinalizar que as populações podem ser contempladas por tratamentos jurídicos distintos, o que gera desafios de proteção para o Estado e para a sociedade. Apesar das distinções principiológicas, Murillo (2008) destaca a complementariedade entre a migração e a proteção de refugiados. Atualmente, o fluxo na fronteira da Venezuela com o Brasil representa um exemplo dessa situação não homogênea. A conjuntura venezuelana tem feito com que muitos migrantes cruzem a fronteira com o Brasil a fim de encontrar melhores condições econômicas ou em virtude de fundado temor de perseguição, sobretudo diante da situação política e da violência que se alastra no país.

Em uma breve análise dos institutos legais que guiam o tema, a lei brasileira de refúgio (Lei $\mathrm{n}^{\circ}$ 9.474/1997) não reconhece, dentre os cinco motivos de perseguição, a migração econômica. O Estatuto do Estrangeiro (instituído pela Lei n ${ }^{\circ}$ 6.815/1980), vigente até pouco tempo, não apresentava solução migratória viável e o acordo de residência do Mercosul não abarca a Venezuela. A Nova Lei de Migração (Lei $n^{\circ} 13.445 / 2017$ ) entrou em vigor no dia 21 de novembro de 2017, seguida pelo Decreto Regulamentador $n^{0} 9.199 / 2017$, sujeito a novas vias de regulamentação. Diante de tal quadro normativo, o aparato legal brasileiro não previa regularização migratória para casos como o da Venezuela, e sua população via na solicitação de refúgio uma solução para a permanência temporária no Brasil.

Com o advento da Resolução Normativa n ${ }^{\circ} 126$ do Conselho Nacional de Imigração (CNIg) - formulada e pleiteada sobretudo por organizações da sociedade civil -, a concessão de residência foi expandida à população de países associados ao MERCOSUL, e a população venezuelana recebeu o direito à permanência por dois anos no Brasil. Dados emitidos pela Polícia Federal e publicados pela Human Rights Watch (2017), de 2014 a dezembro de 2016, cerca de 12.000 venezuelanos entraram no país ${ }^{1}$. Organizações que atuam diretamente em Roraima afirmam que o número cresceu consideravelmente. O mesmo relatório aponta, de acordo com informação cedida pelo Ministério da Justiça, que até dezembro de 2016, 4.670 venezuelanos haviam entrado com o pedido de refúgio (HUMAN RIGHTS WATCH, 2017). Estimase que, com a Resolução Normativa ${ }^{\circ} 126$ do CNIg, diminua-se o número de solicitações de refúgio e cresça o total de solicitações de residência ${ }^{2}$.

Para além do enquadramento nas hipóteses específicas à concessão da proteção internacional do refúgio e para outras condições migratórias, a população que se desloca é marcada por grande diversidade: mulheres, crianças, idosos, não-indígenas e indígenas enfrentam desafios que são comuns para sua acolhida, segurança e proteção, potencializados pelas suas especificidades.

Embora representem um grupo heterogêneo, as mulheres venezuelanas não-indígenas em Boa Vista estão, na mesma proporção, sujeitas a grande vulnerabilidade. Elas compõem cerca de $37 \%$ dos venezuelanos $^{3}$ em Boa Vista, dados do relatório do Observatório das Migrações de 2017 (SIMÕES et al, 2017). No relatório da Human Rights Watch (2017), revelou-se

\footnotetext{
${ }^{1}$ Disponível em <https://www.hrw.org/pt/news/2017/04/18/302397>. Acesso em: 09 dez. 2017

${ }^{2}$ Segundo dados do Comitê Nacional para Refugiados (CONARE), apenas em 2016 houveram 3375 solicitações de refúgio de venezuelanos. Em comparação ao ano anterior, ocorreu um aumento de $307 \%$ no número de solicitações de refúgio. Disponível em: < http://www.justica.gov.br/news/brasil-tem-aumento-de-12-no-numero-de-refugiados-em-2016/20062017_refugio-em-numeros-2010-2016.pdf/view>. Acesso em: 03 ago. 2018.

${ }^{3}$ Disponível em: <http://obmigra.mte.gov.br/index.php/publicacoes-obmigra $>$. Acesso em 07 dez. 2017
} 
que muitas mulheres venezuelanas que se encontram na capital do estado de Roraima, e que receberam o comprovante do agendamento para solicitar refúgio, estão em situação de prostituição por não haver carteira de trabalho ou oferta de emprego. Muitas vezes elas não denunciam crimes sofridos ou testemunhados - como roubos, agressões, sequestros e estupro - em virtude de temor de deportação.

Nesse contexto, mostra-se essencial a reflexão sobre como as mulheres se inserem nos fluxos migratórios atuais, em especial a migração de mulheres venezuelanas em Roraima. Faz-se necessário refletir como estas mulheres estão sujeitas à vulnerabilidades e riscos, desde os abusos durante as travessias até as condições de sobrevivência ao se estabelecerem no país de destino. Para além disso, as mulheres ainda tendem a assumir o protagonismo dos meios de sobrevivência, o que muitas vezes é a própria causa de suas vulnerabilidades.

Tendo isto em vista, propomos, por meio de uma abordagem qualitativa de pesquisa social, recorrer à pesquisa bibliográfica a fim de resgatar uma discussão teórico-analítica que contribua para melhor compreendermos a migração feminina venezuelana em Roraima. O seu desdobramento esbarra na migração sexual, na prostituição e no debate acerca da maneira com que o aparato estatal lida com a vulnerabilidade desta população.

Sendo assim, após considerações iniciais sobre fluxos migratórios mistos e o objeto do nosso estudo, na primeira seção pretendemos fazer uma abordagem das questões de gênero e como se dá a atuação do Estado diante da temática, pela ótica de Carole Pateman, no Contrato Sexual (1988), e também pelos insumos teóricos de Farah (2004) e Piscitelli (2008). Na segunda seção, faremos uma reflexão sobre "feminização das migrações", em que traremos ao debate autoras como Dutra, Santin, Bodega (2014) e Parella (2003); na terceira seção, buscaremos discorrer sobre os desafios de políticas públicas voltadas à migração feminina, à luz dos conceitos de subinclusão e superinclusão de Creshaw (2002). Por fim, apresentaremos a necessidade da concepção de políticas públicas para mulheres migrantes e refugiadas de forma conjunta à sociedade civil e à população beneficiada por tais ações, com base na reflexão de que o aparato estatal brasileiro encontra muita dificuldade de formação de políticas públicas que contemplem a pluralidade da população venezuelana. Esse fluxo acaba por dificultar a proteção de grupos que requerem proteção específica, sobretudo que entreveja a interseccionalidade de ser mulher, trabalhadora e estrangeira.

\section{O ESTADO PATRIARCAL E A PERCEPÇÃO DE GÊNERO}

Em 1988, Carole Pateman, em sua obra O contrato sexual, reinterpreta a história do contrato original, o qual deu origem a uma nova forma de sociedade civil e a formas de relações sociais a partir da perspectiva do sexual-social. À luz da dicotomia das esferas pública-privada, a autora afirma que o contrato sexual - interpretado na obra como uma história de sujeição - é omitido tanto pelos teóricos quanto pelos críticos do contrato original ao firmarem suas teorias unicamente na esfera pública da liberdade civil. À esfera privada - e, consequentemente, aos contratos estreitamente relacionados à esta esfera - não é atribuído um valor político relevante (PATEMAN, 1988).

Embora cada abordagem teórica absorva e elabore conceitos e categorias de forma distinta, tornando o pensamento feminista heterogêneo (PISCITELLI, 2008), a obra de Pateman se faz importante ao estabelecer o contexto histórico de apagamento e subordinação da mulher. A polaridade dos espaços ocupados por homens e por mulheres e o poder exercido também podem ser compreendidos através da percepção teórica das diferenças, como sustenta Carvalho (1998 apud FARAH, 2004). Assim, evidenciam-se conjunturas binárias como "masculino e feminino, produção e reprodução, e público e privado" (FARAH, 2004, p. 48).

A mesma estrutura social fragmentada também se replica em diferentes situações. A falsa dicotomia entre o público e o privado também é descrita por Mirjana Morokvasic (1984), ao afirmar que as necessidades das mulheres no que diz respeito ao contexto migratório são frequentemente rotuladas como privadas ou individuais, enquanto os propulsores masculinos são descritos, inversamente, como externos e públicos.

Outros escritos críticos, por outro lado, assimilando as estruturas de poder como pulverizados e descentralizados (PISCITELLI, 2008), aliam à análise de gênero outras dimensões de diferença, como raça e classe, evidenciando as desigualdades de poder e o 
padrão de dominação e subordinação (FARAH, 2004). Neste sentido, Joan Scott afirma:

Na sociedade, entretanto, os indivíduos não são iguais; sua desigualdade repousa em diferenças presumidas entre eles, diferenças que não são singularmente individualizadas, mas tomadas como sendo categóricas. A identidade de grupo é o resultado dessas distinções categóricas atribuídas (de raça, de gênero, de etnicidade, de religião, de sexualidade... a lista varia de acordo com tempo e espaço e proliferou na atmosfera política da década de 1990) (SCOTT, 2005, p. 23)

Retomando as ideias de patriarcado e experiência (PISCITELLI, 2008) e utilizando-se do conceito de eixos da subordinação, Crenshaw aponta que a interação entre dois ou mais eixos de poder criam intersecções complexas, as quais simbolizam o posicionamento da mulher nos espaços social, político e econômico. Em outras palavras, considerando que o gênero não é o único fator de discriminação, uma mulher pode enfrentar diversas opressões quando não se consideram as vulnerabilidades interseccionais (CRENSHAW, 2002).

Desta maneira, é demonstrado que o contrato original, ao possibilitar o surgimento de uma estrutura social patriarcal moderna, concebera o direito dos homens ao corpo feminino e o acesso sistemático a ele (PATEMAN, 1988). Ao mesmo tempo, a concepção das múltiplas categorias de diferenciação traz luz à compreensão do posicionamento das mulheres na sociedade de forma desigual. Aliando-se à elaboração de estrutura patriarcal moderna trazida por Carole Pateman, torna-se evidente a complexidade na análise das políticas públicas para estas mulheres migrantes.

\section{REFLEXÕES SOBRE A MIGRAÇÃO FEMININA EM RORAIMA}

A partir da segunda metade do século XX e, especialmente, a partir dos anos 1990, a significante feminização dos fluxos migratórios impulsionou novas abordagens das dinâmicas migratórias desde a perspectiva de gênero. Esta nova aproximação, entretanto, evidenciava também alguns desafios, visto que as análises a respeito das migrações estiveram, historicamente, desvinculadas das questões de gênero e das suas demandas (PACECCA, 2011).
De acordo com Lisboa (2006), os estudos migratórios e as teorias clássicas invisibilizaram, por vezes, o papel da mulher no contexto das migrações, concentrando-se na percepção da migração masculina. Nesta conjuntura, a mulher era concebida como completamente dependente do homem e, assim, a compreensão da conjuntura de migração feminina, como as motivações e características da mobilidade interna e externa, foi negligenciada. Ainda, ao ignorar a perspectiva de gênero, as políticas sobre migração acabam por afetar as mulheres de tal forma que impedem o seu reconhecimento enquanto atores sociais (PIZARRO, 2003).

À luz da sustentação de Mirjana Morokvasic (1984) para uma abordagem das migrações femininas sob a perspectiva de gênero - integrando à análise as complexidades laborais e domésticas destas mulheres, assim como a percepção do papel social e suas interações -, Pacecca (2011) afirma que esta perspectiva evidenciou as intersecções entre as discriminações vivenciadas pelas mulheres que fazem parte deste contexto migratório, sejam elas de gênero, étnicas, raciais, nacionais ou de exploração laboral, o que coloca essas mulheres migrantes em situações de particular vulnerabilidade.

Isto posto, evidencia-se que a dimensão da violência vivenciada pelas mulheres refugiadas pode ser compreendida como difusa e interseccionalizada. Segundo Pizarro (2003), as mulheres migrantes, assim como as crianças, experienciam vicissitudes negativas que lhes são quase exclusivas. Não raro, as mulheres são expostas a situações de violência sexual e de gênero - como a exploração sexual e tráfico de mulheres -, violência cultural - discriminação em relação à religião exercida - e violência social - através da manutenção da pobreza, submetendo essas mulheres à condições laborais precárias ou análogas à escravidão (SCHWINN; COSTA, 2016).

Ademais, todo o estigma enfrentado por ser mulher e migrante em uma sociedade orientada por sistemas de poder e dominação que, como afirma Pateman (1988), se estrutura hierarquicamente, produzindo "arranjos singulares na violência de gênero" (SILVEIRA; NARDI, 2014, p. 15), aponta que as políticas são insuficientes não apenas para romper com a violência física, como também com a violência simbólica. 
A intensificação da participação das mulheres como protagonistas dos fluxos migratórios internacionais é algo que chama a atenção quantitativamente, mas, por outro lado, é expressiva a contribuição que traz a análise qualitativa dessa modalidade de migração, uma vez que sugerem implicações sociais das mais diversificadas, devido à centralidade histórica que a figura da mulher detém no núcleo familiar e comunitário (DUTRA; SANTIN; BOTEGA, 2014).

A sobreposição dos papéis sociais (PARELLA, 2003) que recaem sobre a mulher migrante condiciona a sua integração na sociedade do país de destino. Para as mulheres venezuelanas, somam-se as barreiras linguísticas, a xenofobia, a inexistência de uma rede social e a dificuldade de acesso e conhecimento das políticas públicas de saúde e educação.

No contexto de Roraima, o aumento do fluxo migratório de mulheres venezuelanas pode ser percebido através do relatório da organização internacional Human Rights Watch, elaborado para o contexto da Venezuela, no qual é indicado o que o número de mulheres venezuelanas atendidas no Hospital MaternoInfantil Nossa Senhora de Nazareth dobrou no ano de 2016. O mesmo ocorreu no hospital maternidade do Hospital Geral de Roraima: o número de atendimentos de mulheres venezuelanas passou de 368 em 2014 para 807 em 2016. Muitas delas passaram por procedimentos cirúrgicos e outras apresentaram complicações na gravidez devido à falta de acompanhamento pré-natal (HUMAN RIGHTS WATCH, 2017).

Sincronicamente aos dados trazidos pela HRW

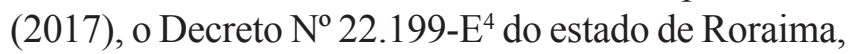
publicado pelo Diário Oficial em 6 de dezembro de 2016, aponta que o município de Pacaraima, o qual faz limite com a Venezuela, realizou um total de 288 pré-natais entre os meses de janeiro e agosto de 2016 , sendo mais da metade dos procedimentos realizados em mulheres venezuelanas $(52,08 \%)$.

O relatório ainda apresentou que, diante desta conjuntura de aumento migratório, estabeleceu-se uma agenda para as solicitações de refúgio no Brasil. Estar na lista de espera representa, entretanto, a impossibilidade de se obter a carteira de trabalho, colocando essa população em situação de vulnerabilidade, passível à exploração trabalhista. Frente a

\footnotetext{
${ }^{4}$ RORAIMA (Estado). Decreto n ${ }^{\circ} 22.199$-E de 06 de dezembro de 2016. Disponível em: <http://imprensaoficial.hospedagemdesites.ws/diarios/doe20161206.pdf>. Acesso em 29 jul. 2018.
}

essa situação de aumento no fluxo migratório, falta de estrutura para uma efetiva garantia dos direitos, dificuldade para o exercício de atividade laboral e inacessibilidade a políticas públicas, somando-se à questão de gênero e nacionalidade, conforme destacado pela Human Rights Watch, mulheres venezuelanas em situação de prostituição em Roraima estão suscetíveis a agressões, sequestros e estupros (HUMANS RIGHTS WATCH, 2017).

\section{A INTERSECCIONALIDADE NAS POLÍTICAS PÚBLICAS}

A compreensão das diferentes opressões vivenciadas pelas mulheres, tais como as expostas anteriormente no caso das mulheres venezuelanas, levou as autoras feministas a reelaborações teóricas a fim de incorporar as diferenças, para além da sexual, ao pensamento feminista. Embora não tenha ocorrido de forma homogênea, as formulações desenvolvidas nas décadas anteriores - como a percepção de gênero como construção social das identidades nos anos 1970 e, posteriormente, a crítica à fixidez e universalidade dos pressupostos relativos aos termos gênero e sexo da década de 1980 - alinhadas à resistência plural feminina, desempenharam um importante papel para a construção de um pensamento crítico, articulando o conceito de gênero a outras categorias de diferenciação, como ao de classe, raça ou sexualidade, a fim de compreender as relações entre as múltiplas diferenças e desigualdades para além do pensamento feminista hegemônico (PISCITELLI, 2008).

Segundo Fonseca (2016), a construção de políticas públicas com recorte de gênero no Brasil, ou seja, "políticas públicas que reconhecem a diferença de gênero e, com base nesse reconhecimento, implementam ações diferenciadas para mulheres" (FARAH, 2004, p. 51, nota de rodapé), é alicerçado no feminismo hegemônico, ou seja, acadêmico e ocidentalizado. Destarte, compreende-se que, assim como as formulações hegemônicas, norteadas por concepções eurocêntricas, não são capazes de analisar as estruturas sociais multidimensionais e complexas, não as compreendendo históricas e culturais e constituída por experiências, os parâmetros utilizados para a elaboração de políticas públicas também ficam limitados a experiências universais e totalizantes. 
Neste sentido, embora mecanismos internacionais para a igualdade de gênero tenham sido criados e estabeleçam avanços conceituais, como indica Kimberlé Crenshaw (2002), tais esforços, formulados a partir de concepções universais, não garantem a efetiva proteção dos direitos humanos das mulheres por não considerarem as diferenças nas vivências experienciadas especificamente por mulheres.

A incorporação da perspectiva de gênero nas discussões acadêmicas e políticas evidencia, ainda, que as mulheres não vivenciam o peso das discriminações da mesma forma. Entretanto, como aponta Crenshaw (2002), a formulação de políticas públicas para mulheres pode apresentar algumas lacunas, o que a autora, com seu conceito de interseccionalidade, define como "superinclusão" ou "subinclusão". Na primeira, a opressão vivenciada por uma determinada parcela das mulheres ou uma condição específica imposta a este grupo são traduzidas como uma questão de gênero, não sendo reconhecidas outras dimensões de subordinação.

A subinclusão, por outro lado, é caracterizada quando um problema ou opressão é vivenciado por uma determinada parcela de mulheres subordinadas e não é percebido como uma questão de gênero por não atingir a parcela dominante das mulheres. Por este ângulo, o enfoque das políticas públicas nas camadas privilegiadas da sociedade não apenas gera análises parciais e distorcidas, como também deixam à margem realidades complexas quando não são compreendidas as experiências diversas (CRENSHAW, 2002).

Analisando a frase "não existe hierarquia de opressão", de Audre Lorde (2015), à luz das políticas públicas, evidencia-se que as opressões são interseccionalizadas. Neste sentido, ao não considerarem esta composição plural e múltipla, as iniciativas são concebidas a partir de uma perspectiva dominante e, ao adquirirem um padrão universalista, mantêm alguns segmentos invisibilizados (FONSECA, 2016).

Desta forma, compreendendo que a vulnerabilidade da mulher refugiada não pode ser dissociada dos múltiplos aspectos nos quais elas estão inseridas (como a raça, a nacionalidade, a classe social e o gênero), ao se considerar apenas um único ângulo, a análise será feita de forma incompleta.

\section{PROPOSTAS DE POLÍTICAS PÚBLICAS ALINHADAS À SOCIEDADE CIVIL}

Tendo em vista que a questão migratória transpassa todos os âmbitos da vida em sociedade e, alinhando-se à perspectiva de gênero e interseccionalidade, que as mulheres migrantes e refugiadas estão sujeitas a vulnerabilidades específicas, evidencia-se a necessidade da incorporação da questão de gênero no processo de formulação de iniciativas, a fim de assegurar a completa proteção dos direitos e de ampliar o acesso a estas garantias.

De acordo com Farah (2004), as políticas públicas têm se tornado um importante cenário de luta e redução das desigualdades entre homens e mulheres. Por este ângulo, tal processo de ampliação das iniciativas existentes e desenho de novas políticas públicas deve alinhar-se também à agenda dos movimentos de mulheres no Brasil para que seja criada uma estrutura que possibilite a redução das desigualdades, o empoderamento e autonomia dessas mulheres, para além da agenda universalista.

Além da incorporação da perspectiva de gênero, é necessário que se formule uma política migratória com base na não discriminação e no fornecimento de serviços exclusivos a imigrantes e refugiadas. Ainda, para que as políticas públicas sejam de fato efetivas, o poder público deve contar com a participação da sociedade civil e a população beneficiada por tais ações nas discussões e formulações, criando-se, assim, um canal de comunicação entre as esferas de interesse.

Desta forma, deverão ser criados mecanismos para que as políticas estejam alinhadas às reais necessidades desta parcela da população e para que as diferentes intersecções sejam consideradas nesta equação. Assim, a concepção de políticas, com a parceria da sociedade civil e das mulheres imigrantes e refugiadas nesses espaços de discussão, torna-se a principal medida para que as vozes sejam ouvidas e para que se construa ações emancipatórias.

Foi nesta perspectiva que, desde 2015, a Secretaria Municipal de Políticas para Mulheres (SMPM) da cidade de São Paulo iniciou o diálogo com movimentos de mulheres imigrantes e refugiadas e representantes da sociedade civil (SÃO PAULO, 2016). Tal iniciativa propiciou uma série de encontros posteriores, os quais discutiram os desafios do processo migratório e as necessidades específicas. 
Destarte, a partir da elaboração de eixos temáticos (como trabalho, saúde, direitos sexuais e reprodutivos, educação, habitação, cultura), estabeleceram-se de diretrizes com o recorte migratório e de gênero para ação governamental a fim de estimular, ampliar e desenvolver políticas interseccionais que atendam mulheres imigrantes e refugiadas e que garantam o pleno acesso aos serviços públicos.

À vista disso, a participação civil, ou seja, o diálogo do poder público com as mulheres imigrantes e refugiadas juntamente com sociedade civil, é primordial para que se compreenda as nuances, a necessidade e, principalmente, as demandas por políticas públicas efetivas.

\section{CONCLUSÃO}

Como apresentado anteriormente, os movimentos migratórios, sejam eles forçados ou não, têm alcançado níveis sem precedentes nos últimos anos. Somando-se ao aumento exponencial dos fluxos migratórios, a heterogeneidade que marca as migrações internacionais tende a adicionar complexidade e desafios à proteção da população imigrante e refugiada.

No que tange a migração venezuelana ao Brasil, as mulheres compõem uma parcela da população exposta diariamente às mais diversas formas de discriminação. Como exposto, estas mulheres estão inseridas em diferentes contextos de subordinação, o que evidencia o caráter interseccionalizado das opressões que vivenciam. Isto significa que as mulheres venezuelanas, dentro deste complexo cenário de mobilidade internacional, apresentam vulnerabilidades que lhes são quase particulares.

No entanto, a atuação estatal tende desconsiderar os elementos específicos e particulares que são trazidos por determinadas parcelas da população imigrante e refugiada e a classificar os distintos grupos migratórios da mesma forma. Tal complexidade deve ser integralmente considerada nas ações políticas e jurídicas do Estado em sua incidência ao regular o fenômeno migratório e ao propor políticas públicas, de acordo com seus interesses ou os compromissos internacionais firmados para este fim. Uma vez que as múltiplas desigualdades são desconsideradas na formulação de medidas e políticas públicas, as diversas opressões experienciadas por estas mulheres também são invisibilizadas.
Percebe-se que cada indivíduo requer uma forma de tratamento específica, em decorrência da sua condição para além do fluxo não homogêneo. Nesse sentido, a complexidade do processo de redistribuição da população vem apontando para a necessidade de incorporar o debate referente ao papel do aparato estatal no preparo de políticas públicas que contemplem a interseccionalidade inerente ao deslocamento da população. Com base nas reflexões apresentadas, além do papel do Estado na concepção de políticas públicas, a contribuição da sociedade civil nesta construção permite trazer visibilidade às especificidades das mulheres imigrantes e refugiadas.

Isto posto, o diálogo entre o Estado e representantes da sociedade civil traz não somente voz à população, mas também permite delinear, de forma conjunta, políticas públicas interseccionais, compreendendo, assim, as complexidades do processo migratório feminino, a fim de garantir e ampliar o acesso de forma integral aos serviços disponibilizados pelo Estado e a criar formas de proteção à esta parcela da população.

\section{REFERÊNCIAS}

BRASIL. Decreto $n^{\circ}$ 9.199, de 20 de novembro de 2017. Regulamenta a Lei no 13.445, de 24 de maio de 2017, que institui a Lei de Migração Disponível em: <http://www. planalto.gov.br/ccivil_03/_ato2015-2018/2017/decreto/ D9199.htm>. Acesso em: 03 ago. 2018.

Lei $n^{\circ}$ 6.815, de 19 de agosto de 1980. Define a situação jurídica do estrangeiro no Brasil, cria o Conselho Nacional de Imigração. Disponível em: <http://www. planalto.gov.br/ccivil_03/Leis/L6815.htm>. Acesso em: 03 ago. 2018.

Lei $N^{\circ}$ 9.474, de 22 de julho de 1997. Define mecanismos para a implementação do Estatuto dos Refugiados de 1951, e determina outras providências. Disponível em: <http://www.planalto.gov.br/ccivil_03/leis/ L9474.htm>. Acesso em: 03 ago. 2018.

Lei $N^{o} 13.445$, de 24 de maio de 2017. Institui a Lei de Migração. Disponível em: <http://www.planalto.gov. br/ccivil_03/_ato2015-2018/2017/lei/L13445.htm>. Acesso em: 3 ago. 2018.

Conselho Nacional de Imigração. Resolução Normativa ${ }^{\circ} 126$, de 02 de março de 2017. Dispõe sobre a concessão de residência temporária a nacional de país fronteiriço. Diário Oficial da União, n. 43, seção 1, 03 mar. 2017. Disponível em: <http://www.acnur.org/fileadmin/ 
Documentos/BDL/2017/11016.pdf >. Acesso em: 03 ago. 2018.

CARVALHO, M. P. Gênero e trabalho docente: em busca de um referencial teórico. In: BRUSCHINI, C.; BUARQUE DE HOLLANDA, H. (Org.). Horizontes plurais: novos estudos de gênero no Brasil. São Paulo: Editora 34, 1998. p. 379409.

\section{COMITE NACIONAL PARA OS REFUGIADOS.} Refúgio em números. 2. ed. 2017. Disponível em: <http:// www.justica.gov.br/news/brasil-tem-aumento-de-12-nonumero-de-refugiados-em-2016/20062017_refugio-emnumeros-2010-2016.pdf/view>. Acesso em: 03 ago. 2018

CRENSHAW, K. Documento para o encontro de especialistas em aspectos da discriminação racial relativos ao gênero. Estudos Feministas. Florianópolis, v. 10, n. 1, jan./abr. 2002, p. $171-188$.

DUTRA, D; SANTIN, Ir. T.; BOTEGA, T. Relatório de pesquisa Mulher migrante: agente de resistência e transformação. Brasília: CSEM, 2014. Disponível em: $<$ http://csem.org.br/images/livros/caminhos/Relatorio_de pesquisa_CSEM_Mulheres_migrantes.pdf $>$ Acesso em: 9 de dezembro de 2017.

FARAH, M. F. S. Gênero e políticas públicas. Estudos feministas, Florianópolis, v. 12, n. 1, jan./abr. 2004, p. 47-71.

FONSECA, L. G. D. Despatriarcalizar e decolonizar o Estado brasileiro - um olhar pelas políticas públicas para mulheres indígenas. Tese (Doutorado em Direito). Universidade de Brasília, UnB. 2016

HUMAN RIGHTS WATCH. Venezuela: Crise Humanitária Alastra-se para o Brasil. Washington, 2017. Disponível em:

$<$ https://www.hrw.org/pt/news/2017/04/18/302397>. Acesso em: 09 dez. 2017.

LISBOA, T. K. Gênero e Migrações: trajetórias globais, trajetórias locais de trabalhadoras domésticas. REHMURevista Interdisciplinar da Mobilidade Humana. v.14, n. 26 e 27, 2006, p. 151 - 166. Disponível em <http://www.csem. org.br/remhu/index.php/remhu/article/view/39/31>. Acesso em 08 dez. 2017

LORDE, A. Não existe hierarquia de opressão. Geledés, 2015. Disponível em: <http://www.geledes.org.br/naoexiste-hierarquia-de-opressao/>. Acesso em: 08 dez. 2017.

MOROKVASIC, M. Birds of Passage are also women. Internacional Migration Review. v. 18, n. 4, 1984, p. 886907.

MOTA, I. Introdução. In: IORIO, J.; PEIXOTO, J. Crise, imigração e mercado de trabalho em Portugal: retorno, regulação ou resistência. Lisboa: Princípia, 2011.

MURILLO, J. C. A proteção internacional dos refugiados na América Latina e o tratamento dos fluxos migratórios mistos.
In: Refúgio, Migrações e cidadania. Caderno de Debates 3, Brasília: ACNUR, IMDH, 2008.

PACECCA, M. I. La migración de mujeres en clave de género y derechos en tres relatorías especiales de las Naciones Unidas. Mora (B. Aires), Ciudad Autónoma de Buenos Aires, v. 18, n. 2, dez. 2012. Disponível em: <http://www.scielo. org.ar/scielo.php?script=sci_arttext\&pid=S1853-1X201200 0200002\&lng $=$ es\&nrm=iso $>$. Acesso em: 27 nov. 2017.

PARELLA, S. R. Mujer, inmigrante y trabajadora: la triple discriminación. Barcelona: Anthropos, 2003.

PATEMAN, C. O contrato sexual. Tradução Marta Avancini. Rio de Janeiro: Paz e Terra, 1993.

PISCITELLI, A. Interseccionalidades, categorias de articulação e experiências de migrantes brasileiras. Sociedade e Cultura, v. 11, n. 2, jul/dez. 2008, p. 263-274.

PIZARRO, J. M. El mapa migratorio de América Latina y el Caribe, las mujeres y el género. Nações Unidas, Santiago de Chile, v. 44, 2003 (Série Población y desarollo)

RORAIMA (Estado). Decreto Estadual no 22.199-E, de 06 de dezembro de 2016. Dispõe sobre a declaração de Emergência em Saúde Pública de Importância Nacional - ESPIN nos municípios de Pacaraima e Boa Vista em decorrência dos impactos ocasionados pelo intenso e constante fluxo migratório no Sistema Único de Saúde, e dá outras providências. Roraima: Diário Oficial (Estado), n. 2897, 06 dez. 2016. Disponível em: <http://imprensaoficial. hospedagemdesites.ws/diarios/doe-20161206.pdf>. Acesso em 29 jul. 2018.

SÃO PAULO. Prefeitura Municipal de São Paulo. Mulheres imigrantes e refugiadas e a luta por políticas públicas na cidade de São Paulo. São Paulo, 2016. Disponível em: $<$ http://www.modefica.com.br/arquivos/cartilhas/cartilhamulheres-imigrantes-refugiadas-luta-por-politicas-publicassp.pdf $>$. Acesso em 28 nov. 2017.

SCHWINN, S. A; COSTA, M. M. M. Mulheres refugiadas e vulnerabilidade: a dimensão da violência de gênero em situações de refúgio e as estratégias do ACNUR no combate a essa violência. Signos, Lajeado, v. 37, n. 2, 2016, p. 216234. Disponível em: $<$ http://www.univates.br/revistas/index. php/signos/article/viewFile/1100/1071>. Acesso em: 05 dez. 2017.

SCOTT, J. W. O enigma da igualdade. Estudos feministas, Florianópolis, v. 13, n. 1, p. 11-30, jan./abr. 2005. SILVEIRA, R. S; NARDI, H. C. Interseccionalidade gênero, raça e etnia e a lei Maria da Penha. Psicologia \& Sociedade, Porto Alegre, v. 26, n. spe, 2014, p. 14-24.

SIMÕES, G. et al. Perfil sociodemográfico e laboral da imigração venezuelana no Brasil: Resumo executivo. Conselho Nacional de Imigração. Brasília, DF: CNIg, 2017. Disponível em: <http://obmigra.mte.gov.br/index.php/ publicacoes-obmigra $>$. Acesso em 07 dez. 2017 